\title{
Some personality traits of believers in extraordinary phenomena*
}

\author{
GEORGE WINDHOLZ and LOUIS DIAMANT \\ University of North Carolina at Charlotte, Charlotte, North Carolina 28213
}

\begin{abstract}
A scale of belief in extraordinary phenomena and one of three personality inventories, the MMPI, TDOT, and MPI were administered to each of 297 college students. Scores on the scale of beliefs in the extraordinary phenomena correlated with several of the personality traits, indicating the tendency of believers in such phenomena as reincarnation, witchcraft, ESP, and astrology to have higher scores on personality scales that would characterize a person as impulsive rather than controlled, reflective rather than practical, neurotic rather than well adjusted, and showing responses characteristic of a schizoid group.
\end{abstract}

The belief in a certain kind of phenomena, here named "extraordinary," appears to be widespread. On the bulletin boards of college campuses, one can see a variety of announcements of meetings of groups interested in yoga and meditation. Newspapers feature astrological columns. Cults dealing with the occult seem to flourish. The London weekly magazine, The Sunday' Times, obtained over 8,000 completed questionnaires inquiring about the extent of belief in ESP, life after death, premonitions coming true, astrology, etc. The sample was by no means representative of the English people (the bulk of respondents being members of the better educated classes), yet it is indicative of the extensiveness of beliefs in these phenomena. Results showed that a majority of respondents gave some credence to ESP, communication with the deceased, and astrology, with a sizable minority of respondents expressing belief in the reality of phenomena ranging from UFOs to the Loch Ness Monster (Evans, 1972).

The present study attempts to throw some light upon the personality characteristics of the believers in extraordinary phenomena. and so it becomes mandatory to define these events. Under the term extraordinary phenomena are understood to be beliefs, preoccupations, and practices connected with (a) phenomena that are outside of the Judeo-Christian tradition and more closely connected with the traditional Hindu culture, such as Yoga, meditation, and the concept of reincarnation: (b) beliefs on the fringes of the Western tradition, such as astrology, ghosts, magic, and witchcraft: (c) possibly natural phenomena, yet such as evoke an aura of mystery and sensationalism, such as ESP, UFOs, some aspects of hypnosis, dreams, and death.

\section{PROCEDURE}

Subjects

Ss were 297 male and female undergraduates enrolled in

*This research was supported by a grant from the Faculty Research Committee of the University of North Carolina at Charlotte. Robert Thorndike sponsors it and takes full editorial responsibility for its contents. laboratory sections of an introductory course in psychology at the University of North Carolina at Charlotte. Ss were divided in 14 sections. All test materials were completed during the laboratory sessions.

\section{Administration of Materials}

Each $\mathrm{S}$ was administered 38 items in a questionnaire that dealt with extraordinary phenomena (the Scale of Beliefs in Extraordinary Phenomena, or SOBEP). In addition, different groups completed one of the following personality inventories: the Minnesota Multiphasic Personality Inventory (MMPI) (Hathaway \& McKinley, 1943), the Thorndike Dimensions of Temperament (TDOT) (Thorndike, 1966), and The Maudsley' Personality Inventory (MPI) (Eysenck, 1962).

\section{Scale Construction}

To establish the degree of the Ss' belief in the extraordinary phenomena, a self-descriptive scale was constructed. Initially, the relevant literature - the verbal statements of the proponents of extraordinary beliefs-was collected. On the basis of these data, 55 positively worded statements were made up and arranged in Likert-type scales, with five alternatives ranging from agree to disagree. These items were administered to $72 \mathrm{Ss}$ enrolled in undergraduate psychology courses at the University of North Carolina at Charlotte. A subsequent analysis of responses to each statement in terms of discriminating power reduced the number of statements to 38 .

These remaining statements were administered (together with the three personality instruments) to a total 349 Ss. Fifty-two protocols were excluded as incomplete. The remaining 297 protocols were subjected to an item-total analysis. Three items were excluded. The final Scale of Beliefs in Extraordinary Phenomena (SOBEP) 1 consists of 35 items such as: "A person who died may be reborn as another person." "Dreams do foretell future." "One can understand a person's personality by studying his handwriting."

\section{Treatment of Data}

The SOBEP scores were correlated with the three personality measurement instrument scores mentioned above (Pearson product moment). The split-half reliability of the SOBEP, corrected by the Spearman-Brown prophecy formula, ranges from .91 to .92 in the different groups studied.

\section{RESULTS}

The correlation of personality trait scores to the belief in extraordinary phenomena scores are given in Table 1. Results indicate three interrelated elements. The first indicates a positive relationship between SOBEP scores, 
Table 1

Correlation Between the SOBEP and Certain Personality Trait Scores

\begin{tabular}{|c|c|c|c|}
\hline Instrument & $\mathrm{N}$ & Traits & $\mathrm{I}$ \\
\hline MMPI & 72 & $\begin{array}{l}\text { Hypochondriasis } \\
\text { Depression } \\
\text { Hysteria } \\
\text { Psychopathic Deviate } \\
\text { Masculinity-Femininity } \\
\text { Paranoia } \\
\text { Psychasthenia } \\
\text { Schizophrenia } \\
\text { Hypomania }\end{array}$ & $\begin{array}{l}.31 \div \\
.05 \\
.08 \\
.16 \\
.02 \\
.03 \\
.20 \\
.30 \div \\
.36 \div\end{array}$ \\
\hline TDOT & 103 & $\begin{array}{l}\text { Social } \\
\text { Ascendant } \\
\text { Cheerful } \\
\text { Placid } \\
\text { Accepting } \\
\text { Tough-Minded } \\
\text { Reflective } \\
\text { Impulsive } \\
\text { Active } \\
\text { Responsible }\end{array}$ & $\begin{array}{l}-.17 \\
.09 \\
-.05 \\
-.03 \\
-.02 \\
-.02 \\
.27 \div \\
.23^{*} \\
-.06 \\
-.14\end{array}$ \\
\hline MPI & 122 & $\begin{array}{l}\text { Extroversion } \\
\text { Neuroticism }\end{array}$ & $\begin{array}{l}.05 \\
.21^{*}\end{array}$ \\
\hline
\end{tabular}

*Significant at the .05 level in a two-tailed test. tSignificant at the .01 level in a two-tailed test.

respectively, and the impulsive trait scores of the TDOT and the hypomania scores of the MMPI, showing that the higher the held belief in extraordinary phenomena, the higher the propensity to action at the spur of the moment. The positive correlations of the neuroticism scores of the MPI and the hypochondriasis scores of the MMPI with the SOBEP scores indicate complaints about bodily ailments, a general dissatisfaction, a lack of emotional stability, and, on the whole, a subjective state of suffering so often associated with neuroticism for Ss higher on the SOBEP scale. The positive correlation obtained between the SOBEP scores and the reflective scores of the TDOT imply a greater tendente of the believers in extraordinary phenomena to be interested in ideas. and to speculate and reflect. especially on the more abstract level. The relatively higher correlation between the SOBEP scores and the schizophrenia scores of the MMPI indicate a tendency toward bizarreness in thought pattern and behavior for Ss higher on the SOBEP xale.

\section{DISCUSSION}

The results in the study allow fir a tentative desiption of the individuals who show a tendenc w acep: a rcall a w of phenomena that are best described a sutraurdinary: that is. vach phenomena that are on the periphers of belicts of Hescrm thought, or, that. while within the realm of empirical confirmation, are vet associated with semsational aspects

The "believers" have neurotic tendencies that exper themselves in subjective suffering and complaint about somatic symptoms. These individual alo have a gercater propensity action. especially of the impulsive sort. rather than firs deliberate. planned action. Dissatisficd and impulsivel! motivated. they have a tendency to reflect. where the content of their thought is of abstract rather than concrete nature. Apparently, their general dissatisfaction sxpresses itself in the more emotional rather than objective thought proceses. Hence. the tendency is toward private, more fantastic contents of beliefs that characterize the schizophrenic thinking.

\section{REFERENCES}

Evans, C. A question of belief. The Sunday Times Magazine (London), March 26, 1972. Pp. 36-39.

Eysenck, H. J. The Maudsley Personality Inventory. San Diego, California: Educational and Industrial Testing Senice, 1962 .

Hathaway, S. R., \& McKinley, J. C. Minnesota Multiphasic Personality Inventory. New York: The Psychological Corporation, 1943

Thorndike, R. L. Thorndike Dimensions of Temperament. New York: The Psychological Corporation, 1966.

\section{NOTE}

1. The SOBEP is available from the authors upon request.

(Received for publication November 15. 1973.) 